\title{
Microwave-alkaline treatment for enhanced disintegration and biodegradability of meat processing sludge
}

\author{
Balázs Lemmera, Petra Veszelovszki-Kovács ${ }^{\mathrm{b}}$, Cecilia Hodúra, Sándor Beszédesa,* \\ ${ }^{1}$ Department of Process Engineering, Faculty of Engineering, University of Szeged, Moszkvaikrt. 9., H-6725 Szeged, Hungary, \\ email:lemmer@mk.u-szeged.hu (B.Lemmer), hodur@mk.u-szeged.hu (C. Hodur), beszedes@mk.u-szeged.hu (S. Beszédes) \\ ${ }^{2}$ Technical Institute, Faculty of Engineering, University of Szeged, Moszkvaikrt. 9., H-6725 Szeged, Hungary, \\ email:veszelov@mk.u-szeged.hu
}

Received 15 June 2017; Accepted 29 November 2017

\begin{abstract}
A B S T R AC T
An increasing number of studies has been focused on the investigation of sludge treatment by microwave irradiation alone or combined with chemical methods. Besides the promising results for municipal sludge processing, the applicability of microwave pre-treatment methods is less evaluated and verified for food industry sludge, especially in continuous-flow operations. Therefore, our work is aimed at the investigation of microwave-alkaline treatment for meat processing sludge using disintegration degree (DD) and aerobic biodegradation index (BDI) as control parameters. Our results verified that irradiated microwave energy $\left(E_{s}\right)$, calculated from microwave power and flow rate applied during continuous flow microwave process, and alkaline dosage also have a significant effect on disintegration degree and aerobic biodegradability. With microwave-alkaline treatment the DD was improved to over $45 \%$ from the initial value of $12 \%$. The change of BDI cannot be described by the same tendency that obtained for DD. Due to the combined treatment, the BDI was improved from $7.8 \%$ to $25 \%$, but over a certain value of $E_{s}$ and alkaline dosage, the aerobic biodegradability starts to worsen. Measurement of dielectric constant has been proved suitable to detect the physicochemical changes in sludge structure due to microwave-alkaline treatment, and behaviour of dielectric constant as a function of $E_{s}$ and alkaline dosage show a tendency similar to that which obtained for DD. These preliminary results enable the further and deeper analysis of dielectric parameters of sludge in order to find suitable real-time and/or in-line method to estimate the disintegration efficiency during sludge treatment processes.
\end{abstract}

Keywords: Sludge; Microwave; Alkaline treatment; Disintegration; Biodegradability; Dielectric constant

\section{Introduction}

Due to the increasing number of wastewater treatment plants and the widening of industrial wastewater pre-treatment facilities, sludge production has been increasing. A new way of sludge handling should be developed because the regulations for agricultural utilisation and landfilling have become restricted, and the social acceptation of incineration has worsened during recent years. Anaerobic digestion or composting, as a controlled biological degradation process, is suitable to handle a large sludge volume. Fur-

*Corresponding author. thermore, anaerobic digestion is capable of producing biogas, which is considered suitable for achieving sustainable energy supply for high-density settlements and for rural areas [1]. But sludge needs pre-treatment before biological utilisation in order to increase the dry matter content, kill the pathogens, improve the dewaterability, and/or enhance the biodegradability. Application of microwave irradiation as a sludge pre-treatment method has been more and more often investigated [2]. It can be summarised that microwave irradiation increases to a larger extent the organic matter solubility and biodegradability of sludge than that achievable by conventional thermal methods. Moreover,the time required for the microwave process is significantly less than 
that of other conventional methods. Microwave irradiation after a short exposure time can disrupt the cell walls and cell membranes, which increases the concentration of soluble organic matter in sludge liquor and the ratio of free to bounded water [3]. Furthermore, the oscillating electromagnetic field weakens the binding force between extracellular polymers of sludge which leads to effective floc breakage [4]. From energy and economic aspects, a combination of the microwave irradiation with sonication as a two-stage process could be a promising alternative for conventional sludge pre-treatment technologies [5]. It can be noticed that change of biodegradability and solubilisation are not in direct correlation because some solubilised components have been transformed to low biodegradability form due to the thermochemical pre-treatment and act as inhibitor during the anaerobic digestion process [6].

Food industry wastewater sludge, such as meat processing sludge or dairy industry sludge, contains proteins, carbohydrates and, in some cases, lipids in high concentration. Because of the dissociated proteins and carbohydrates negative, charges are formed and attached to the surface of sludge particles. Therefore, during sludge conditioning followed by dewatering methods, cations are dosed to compensate the repel effects between the particles and to improve the flock building. In high water contented materials due to the high-frequency oscillating polarity electromagnetic field, the temperature of polar water molecules increased to a higher extent than macromolecular components or apolar molecules. The different heating rates of components that occurred by different dielectric parameters can be utilisable for separation, for instance. The overall heat generation capability of microwave irradiation is correlated to dielectric properties, which are determined by the applied frequency, temperature, composition and physicochemical structure of materials [7]. The complex permittivity is used to characterise the dielectric behaviour of materials in an electromagnetic field. Dielectric constant is the real part of complex permittivity that indicates the polarisation ability of materialsor the ability of a material to store the external electric field. The dielectric loss factor is the imaginary part of the complex permittivity, measuring the ability of material for energy dissipation or indicating the capability for heating in an electromagnetic field [8].

For the heating effect of microwave irradiation, dipolar rotation and ionic conduction can play a role. In an electromagnetic field charge, polarisation occurs if materials contain free electrons. Dipoles orientate according to the polarity of the high-frequency electromagnetic field. If dipoles lag behind the electromagnetic field, the molecular friction leads to energy dissipation and results in heat generation [9]. If ions are dissolved in the materials, the alternating electric field creates an electric current, and because of the internal resistance, it results in heat generation. Comparing the thermal efficiency of these two mechanisms, the ionic conduction has more strength effect than dipolar rotation.

Among the chemical sludge pre-treatments, alkaline dosage is a low-cost and easily controllable method. Alkaline pre-treatment alone is suitable to enhance the organic matter solubilisation and to degrade extracellular polymers, which limit the direct biological degradation. The effi- ciency of alkaline pre-treatment can be increased by thermal methods (such as thermochemical pre-treatment). Microwave irradiation combined with alkali dosage increases the disintegration degree of sludge particles and improves the biogas yield from waste-activated sludge [10]. It was verified that irradiated specific energy and applied power also have effects on biogas production. Irradiated energy determines mainly the maximum achievable organic matter solubility, biogas yield and the overall energy efficiency of the process, but microwave power has an effect on methane production rate and organic loading rate applicable to continuously operate reactors [11].

Controlling of temperature pattern and other parameters related to thermal efficiency (change of penetration depth, power dissipation, etc.) during the microwave irradiation are the key issues for the development of continuous-flow microwave process and/or the scale up [12]. The energy carried by microwave irradiation at a frequency of $2450 \mathrm{MHz}$ is not enough to disrupt covalent and hydrogen bounds [13]. But low energy density along with high-frequency electromagnetic field can be proposed to unfold other structural changes in proteins. These structural changes have the potential to affect the enzyme activity as well. It can be noticed that structural changes are also determined by the strength of applied electric fields which depend on the instrumental characteristics [14].

Besides the appreciation of promising results in the field of microwave conditioning for municipal sludge, it can be worthwhile to extend the research investigation into the efficiency of microwave treatment for food industry sludge with higher organic matter content. Moreover, besides the examination of the change in anaerobic digestion, the biodegradation under aerobic condition could provide additional information to evaluate the efficiency of microwave irradiation as a potential pre-treatment method. Therefore, the aim of our work was to investigate the effect of microwave-alkali treatment on the disintegration degree and anaerobic biodegradability of meat processing sludge. Another target of our experimental research was the detection of dielectric constant, which led to the hypothesis that change of organic matter solubilisation and disintegration has a correlation with the dielectric behaviour of sludge.

\section{Materials and methods}

Sludge samples originated from the wastewater purification line of a meat processing factory. The sludge produced after chemical precipitation by $\mathrm{FeCl}_{3}$ was followed by a sedimentation phase of $12 \mathrm{~h}$. In the industrial wastewater treatment line, the $\mathrm{FeCl}_{3}$ dosage was in the range of $0.028-0.032 \mathrm{~mol} \mathrm{~m}^{-3}$. Samples were stored in a closed polyethene bag at $4^{\circ} \mathrm{C}$ before processing. Total solid (TS) and volatile solids (VS) content of meat processing sludge were $53 \pm 3.5 \mathrm{~g} \mathrm{~L}^{-1}$ and $6560 \pm 281 \mathrm{mg} \mathrm{L}^{-1}$, respectively. The initial total chemical oxygen demand (TCOD) and soluble COD (SCOD) was determined as $28300 \pm 690 \mathrm{mg} \mathrm{L}^{-1}$ and $3250 \pm$ $212 \mathrm{mg} \mathrm{L}^{-1}$, respectively. The biochemical oxygen demand $\left(\mathrm{BOD}_{5}\right)$ of thickened raw sludge was $724 \pm 51 \mathrm{mg} \mathrm{L}^{-1}$.

Microwave treatments were carried out in a tailor-made microwave unit equipped with variable power magnetron (from $100 \mathrm{~W}$ to $850 \mathrm{~W}$ ) operating at a frequency of 2450 
$\mathrm{MHz}$. In a continuous-flow operation mode, the volumetric flow rate of irradiated samples can be varied by the revolution of the peristaltic pump in the range of $6-35 \mathrm{~L} \mathrm{~h}^{-1}$. The specific irradiated microwave energy $\left(E_{s}\right)$ was determined based on the method described by Yang et al. [15] for batch microwave processes but according to the continuous-flow experimental setup applied in our present work. $E_{\mathrm{s}}\left(\mathrm{J} \mathrm{g}^{-1}\right)$ was calculated from the power of magnetron $\left(P_{m} ; \mathrm{W}\right)$, the quantity of total solids (TS; g) and the volume of sample $(V$; $\mathrm{L})$, the volume of microwave cavity $(V ; \mathrm{L})$, and the volumetric flow rate $\left(Q_{v} ; \mathrm{L} \mathrm{s}^{-1}\right)$ by Eq. (1).

$$
E_{s}=\frac{P_{m}}{m_{T S} Q_{V}} V\left[J g^{-1}\right]
$$

The alkaline dosage was given by the ratio of the quantity of $\mathrm{NaOH}$ to TS content of sludge in $\mathrm{g}_{\mathrm{NaOH}} / \mathrm{g}_{\mathrm{TS}}$ unit.

Total chemical oxygen demand (TCOD) was measured after dilution from whole sludge matrix using the colourimetric method (APHA, 2005). Soluble COD (SCOD) was determined from the supernatant phase of diluted samples after centrifugation (10,000 rpm for $20 \mathrm{~min})$ and pre-filtration by a $0.45 \mathrm{~mm}$ pore-sized disc filter. Disintegration degree (DD) was calculated according to Zhang et al. [16] from the SCOD and TCOD of untreated and treated samples by Eq. (2).

$$
D D=\frac{S C O D_{t}-S C O D_{0}}{T C O D-S C O D_{0}} 100 \quad[\%]
$$

$\mathrm{SCOD}_{0}$ and $\mathrm{SCOD}_{\mathrm{t}}$ mean the chemical oxygen demand of raw and pre-treated samples, respectively.

The change of aerobic biodegradability was characterised by the biodegradation index (BDI) [16]. BDI was calculated from the biochemical oxygen (BOD) and chemical oxygen demand (COD) by Eq. (3).

$$
B D I=\frac{\left(B O D_{5} / S C O D\right)_{t}-\left(B O D_{5} / S C O D\right)_{i}}{B O D_{5 \max } / S C O D_{\max }} 100 \quad[\%]
$$

Biochemical oxygen demand was measured by a respirometric BOD system (BOD Oxidirect, Lovibond, Germany) at a controlled temperature of $20^{\circ} \mathrm{C}$ for $5 \mathrm{~d}$ degradation interval. Subscript $i$ means the parameters of initial (untreated) sludge sample, and $t$ means the parameters determined after microwave treatment. Maximum achievable SCOD and $\mathrm{BOD}_{5}$ were determined from the diluted sludge sample after $24 \mathrm{~h}$ disintegration using 2 mol L-1 $\mathrm{NaOH}$ dosage at $60^{\circ} \mathrm{C}$.

Dielectric constant $\left(\varepsilon^{\prime}\right)$ was measured by a specially designed tailor-made dielectrometer. Microwave magnetron operated at a frequency of $2450 \mathrm{MHz}$, and samples flowed through a cylindrical tube made from PTFE. The effects of samples on the wave form and the intensity of electromagnetic field were by diode power sensors (NRVZ, Rohde \& Schwarz). Diodes were positioned at a distance of $\lambda / 8$. Forwarded waves and returned waves reflected from sample form standing wave. Voltage standing wave ratio (VSWR) can be calculated from the maximum $\left(\mathrm{U}_{\max }\right)$ and minimum $\left(\mathrm{U}_{\min }\right)$ AC voltage detected along the waveguide by NRVZ sensors.
$V S W R=\frac{U_{\max }}{U_{\min }}$

The relationship between VSWR and reflection coefficient $(\Gamma)$ is given by Eq. (5). $\Gamma$

$|\Gamma|=\frac{V S W R-1}{V S W R+1}$

Phase shift $(\phi)$ was determined based on the distance of detected position (d) for minimum voltage (node) in the waveguide from the sample and the wavelength $(\lambda)$.

$\phi=\frac{d \pi}{\lambda}$

$\varepsilon^{\prime}$ was calculated from the reflection coefficient $(\Gamma)$ and detected phase shift $(\phi)$ according to Eqs. (7) and (8).

$$
\begin{aligned}
& \delta=2\left\{\arctan \left[\frac{|\Gamma| \sin \varphi}{1-|\Gamma| \cos \varphi}\right]-\arctan \left[\frac{|\Gamma| \sin \varphi}{1+|\Gamma| \cos \varphi}\right]\right\} \\
& \varepsilon^{\prime}=\frac{1}{\sqrt{1+\operatorname{tg}_{\delta}^{2}}}\left(\frac{1+|\Gamma|^{2}+2|\Gamma| \cos \varphi}{1+|\Gamma|^{2}-2|\Gamma| \cos \varphi}\right)
\end{aligned}
$$

Response surface modelling and analysis was used to investigate the effect of two variables, the irradiated specific energy $\left(E_{s}\right)$ and alkaline dosage, on DD, BDI and dielectric constant. The experiments were based on face-centred central composite design. For the statistical analysis Statistica 13 was used.

\section{Results and discussion}

In the first stage of the experiments, the effect of irradiated specific microwave energy $\left(E_{s}\right)$ and alkaline dosage on the disintegration degree (DD) was investigated. DD is a generally used parameter to control and evaluate the efficiency of thermal, chemical and thermochemical sludge treatments. Results were subjected to ANOVA to determine the main influential treatment parameters and their significances. F-values derived from ANOVA show the strength of factors and their interactions on the investigated control parameter; furthermore, $\mathrm{p}$-value describes the significance of the coefficient of the constructed second-order equations. Analyses of variances for disintegration degree are summarised in Table 1.

Our earlier experiments carried out in batch microwave sludge treatment unit verified that microwave power level and irradiated energy also have significant effects on the biodegradability of food industry sludge [17]. Our present results show that specific irradiated microwave energy (coded as $x_{2}$ ) is the main influential parameters for the disintegration efficiency of microwave treatment. Besides $E_{s^{\prime}}$ the alkaline dosage $\left(x_{1}\right)$ also has a significant effect on sludge disintegration at $95 \%$. These establishments are partially consistent with the results of Yang et al. [15]. In their experiments, microwave-alkaline treatment was investigated, the $\mathrm{pH}$ of sludge was varied in the range from 8 to 12 , and it 
Table 1

Analysis of variance for disintegration degree (DD)

\begin{tabular}{lllllll}
\hline Source & \multicolumn{1}{c}{ SS } & & Df & \multicolumn{1}{c}{ MS } & F-value & p-value \\
\hline$x_{1}$ & 270.68 & 1 & 270.68 & 22.50 & 0.0032 \\
$x_{1}{ }^{2}$ & 87.02 & 1 & 87.02 & 7.24 & 0.0361 \\
$x_{2}$ & 444.93 & 1 & 444.93 & 36.99 & 0.0009 \\
$x_{2}^{2}$ & 50.75 & 1 & 50.75 & 4.22 & 0.0858 \\
$x_{1} x_{2}$ & 1.78 & 1 & 1.78 & 0.15 & 0.7138 \\
Error & 52.17 & 6 & 12.03 & & \\
$\mathrm{R}^{2}$ & 0.9279 & & & & \\
\hline
\end{tabular}

SS: sum of square; Df: Degree of freedom; MS: mean square

was found that $\mathrm{pH}$ has more significant effect on DD than $E_{s}$. But it can be noticed that in their study meat processing sludge with lower total organic matter content (COD of $10,000 \mathrm{mg} \mathrm{L}^{-1}$ ) but higher SCOD was exposed to MW treatment more than the sludge involved in our experiments. Deflocculation can be enhanced by $\mathrm{NaOH}$ dosage. $\mathrm{Na}^{+}$ion is suitable to displace the divalent cations, which stabilise the floc build-up from extracellular polymeric substances and other organic compounds of sludge [18].

The high value of correlation coefficients $\left(R^{2}=0.9279\right)$ shows that the model well describes the correlation between the predicted and observed values in the response. Analysis of variance shows that linear and quadratic terms of alkaline dosage $\left(x_{1}\right)$ and linear terms for $E_{s}\left(x_{2}\right)$ were significant, but quadratic terms for $E_{s}$ and interaction between the two variables were non-significant ( $p$ values of insignificant variables are shown in italics). Eq. (9) shows the constructed mathematical model for DD $\left(Y_{1}\right)$ after the removal of insignificant terms.

$Y_{1}=-10.2+135.8 x_{1}-15.77 x_{1}^{2}+0.05 x_{2}$

In the empirical model developed, all linear coefficients were positive, indicating that microwave irradiation and alkaline dosage assist in sludge disintegration. The increment of alkaline dosage and the application of higher-energy intensity during microwave irradiation enhance the DD. But disintegration degree is limited, i.e. over a certain value of $E_{s}$ and $\mathrm{NaOH}$ dosage, a further increment of DD has not been observed, which is indicated by the negative quadratic term and shows in response surface (Fig. 1).

For meat processing sludge the disintegration degree can be enhanced from $12 \%$ to over $45 \%$ by MW irradiation with over $8,000 \mathrm{~J} \mathrm{~g}^{-1}$ and alkaline dosage over $0.5 \mathrm{~g}_{\mathrm{NaOH}} / \mathrm{g}_{\mathrm{TS}}$ which corresponds to a sludge $\mathrm{pH}$ of $10.8 \pm 0.2$. Yang et al. [15] found microwave-alkaline pre-treatment suitable to increase DD over $70 \%$ but in that study the applied $E_{s}$ was in the range of 19,200 to $48,000 \mathrm{~J} \mathrm{~g}^{-1}$, and saturation value on the tendency of DD increment in the $\mathrm{pH}$ range of 9 to 12 was not observed. Jang and Ahn [19] applied microwave-alkaline pre-treatment for thickened waste activated sludge. In that case, the SCOD/TCOD increased to $53 \%$ from the initial $3 \%$. But pre-treatment temperature of $135^{\circ} \mathrm{C}$ and irradiated energy of 3,600 kJ resulted in that large-scale improvement of disintegration. Rani et al. [20] exposed dairy sludge to different microwave power intensity. They concluded a near-lin-

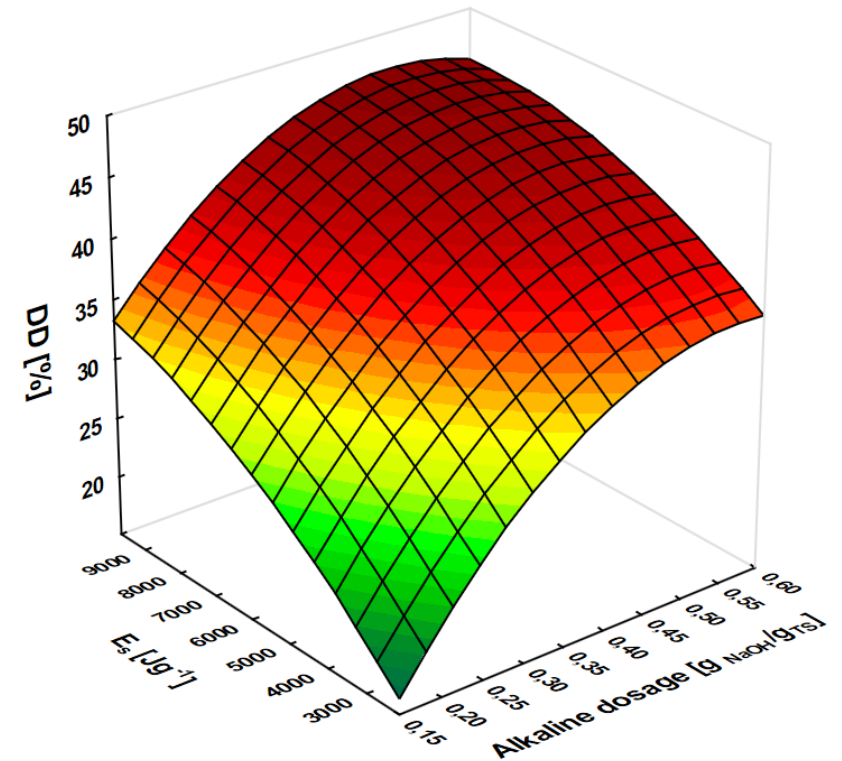

Fig. 1. 3D response surface for DD as a function of alkaline dosage and $E_{s}$.

ear correlation of the release of SCOD with the microwave intensity and irradiation time if specific microwave energy was varied in the range of $108 \mathrm{~kJ} \mathrm{~L}^{-1}$ and $2,333 \mathrm{~kJ} \mathrm{~L}^{-1}$, but at higher intensities saturation value was found for COD solubilisation. Ebenezer et al. [18] investigated the effect of pre-treatment with different microwave energy level on the COD solubilisation of municipal waste-activated sludge. It was concluded that beyond $14,000 \mathrm{~kJ} \mathrm{~kg}^{-1}$ further increment of organic matter solubilisation was not found. Moreover, when energy level exceeded the limit value of 45,000 kJ $\mathrm{kg}^{-1}$, a decreasing tendency was observed. Specific energy need depends on the characteristics of processed sludge. The breaking point of COD solubilisation tendency was determined as $30,000 \mathrm{~kJ} \mathrm{~kg}_{\mathrm{TS}}{ }^{-1}$ for municipal waste-activated sludge by Kavitha et al. [21]. At this high-temperature range, where boiling occurred, COD loss could be due to the evaporation of soluble organic matters.

Sludge solubilisation by microwave pre-treatment was influenced by the TS of the initial COD content as well. Ebenezer et al. [22] concluded that microwave treatment for low TS-contented sludge results in lower COD solubilisation than obtained for high TS-contented sludge. Deflocculating assists to achieve a higher solubilisation efficiency, which was respectively $21 \%$ and $31 \%$ for flocculated and deflocculated municipal waste-activated sludge exposed to the same specific microwave energy level. In this case, the meat processing sludge has higher TS and TCOD content that was used by Ebenezer et al.; therefore, a higher increase in DD verified that the TS content of processed material plays a significant role in the overall efficiency of microwave pre-treatments.

The solubility of organic matters and, therefore, the disintegration degree is used to estimate the biodegradability for sludge [23], but in most cases biodegradability is defined based on anaerobic digestion kinetic or biogas production of sludge. Microwave irradiation, alkaline treatment and their combination are suitable to increase the organic matter removal during anaerobic digestion and 
improve the biogas yield [10;24]. Appropriate microwavealkaline pre-treatments increase the biogas production by $40-200 \%$, depending on the sludge characteristic [10; 25; 26]. Besides these benefits, the advantageous effect of microwave pre-treatment could also manifest in higher anaerobic degradation rate [11].

In our work it is assumed that the change of aerobic biodegradability shows a tendency similar to that observed for DD. The change of biodegradation index shows that BDI has an initial rise if alkaline dosage and / or $E_{s}$ was increased, but after a peak in the overdosing of $\mathrm{NaOH}$ or use of high energy intensity MW treatment, the ratio of biodegradable to total organic matter content worsened (Fig. 2.). In the 5 $\mathrm{d}$ aerobic degradation process, the initial BDI for untreated sludge was $7.8 \%$, and the maximum achievable BDI due to microwave-alkaline treatment was detected as $25 \%$.

This tendency is not agreed as of obtaining for DD. A higher intensity of MW irradiation or an alkaline dosage than the optimum range could result in the formation of a final product or byproduct during decomposition of macromolecules or sludge floc, which is transformed into soluble form but has an inhibitory effect on aerobic microorganisms. This phenomenon was explained by Maillard's reaction in the study of Dwyer et al. [27] and Takashima and Tanaka [28]. The worsening effect of alkaline dosage on BDI could be due to the increased salinity. During the alkalisation of sludge and $\mathrm{pH}$ re-adjustment produce, $\mathrm{NaCl}$ and the aerobic microorganisms lose their activity beyond the salinity tolerance limit. The advantageous effect of alkaline dosage on sludge disintegration was verified by the tendency to change in DD. But over a certain value of alkaline dosage,increasing of the solubility of the substrate could not compensate for the negative effect of increased salinity on biodegradability. It was observed that at high salinity the ions cause enough electrostatic force to break cell membranes, which is manifested as DNA leakage. Therefore, DNA leakage could be considered as an indirect method to determine the change of microbial activity [29]. Wang et al. [30] detected the cell wall destruction effect of increased salinity for denitrifying granular sludge, but enhanced DNA leakage shows that microbial activity worsened.

Considering the effect of process variables on BDI, the analysis of variance shows that the linear term for alkaline dosage $\left(x_{1}\right)$ and linear and quadratic terms for irradiated microwave energy $\left(x_{2}\right)$ have significant effects, but the interaction and quadratic effects of $E_{s}$ were not significant at the 95\% level (Table 2). With respect to F values, similar to the results obtained for DD, the specific irradiated microwave energy has a stronger effect on BDI than alkaline dosage. The second order quadratic empirical model with significant terms for BDI $\left(Y_{2}\right)$ is given by Eq. (10).

$$
Y_{2}=-5.6+55.9 x_{1}+0.005 x_{2}-0.00011 x_{2}^{2}
$$

Another aspect of our research was to investigate the change of dielectric constant in the microwave-alkaline sludge treatment process. Because dielectric constant measurement has a high temperature dependency, the dielectric measurements were carried out for all samples after cooling to $20^{\circ} \mathrm{C}$. The dielectric constant for pure water at room temperature at atmospheric pressure is approximately in the range of 78-80 [31]. There cannot be found studies dealing with the examination of dielectric

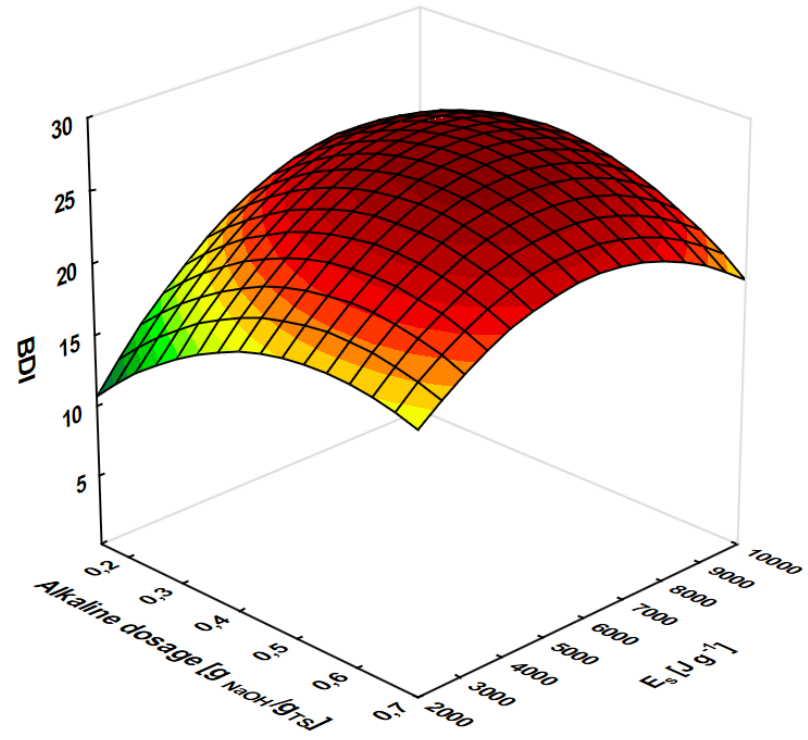

Fig. 2. Response surface for BDI.

Table 2

Analysis of variance for biodegradation index (BDI)

\begin{tabular}{cccccc}
\hline Source & SS & Df & MS & F-value & p-value \\
\hline$x_{1}$ & 24.81 & 1 & 24.81 & 6.27 & 0.0463 \\
$x_{1}{ }^{2}$ & 14.01 & 1 & 14.01 & 3.54 & 0.1089 \\
$x_{2}$ & 75.47 & 1 & 75.47 & 19.07 & 0.0047 \\
$x_{2}{ }^{2}$ & 54.90 & 1 & 54.90 & 13.87 & 0.0098 \\
$x_{1} x_{2}$ & 13.24 & 1 & 13.24 & 3.34 & 0.1172 \\
Error & 16.75 & 6 & 3.96 & & \\
$\mathrm{R}^{2}$ & 0.8994 & & & & \\
\hline
\end{tabular}

parameters for real food industry sludge matrix, such as meat processing sludge. However, the change of dielectric parameters caused by microwave-alkaline treatments has not been investigated yet. In our measurements, at a given temperature and frequency, the composition and physicochemical state of the system determine the dielectric parameters [7]. Due to the ionic and polar components presented in the sample, the dielectric constant determined for meat processing sludge was higher than that obtained for pure water. As our results verified, microwave-alkaline treatment has a strong effect on disintegration degree and these physicochemical changes led to the increment of dielectric constant (Fig. 3.).

The tendency of the change of dielectric constant as a function of $E_{s}$ and alkaline dosage was similar to that obtained for DD (Fig. 1). As DD was enhanced with increased irradiated energy and alkaline dosage, so does the change of dielectric constant show the same behaviour. Considering the results of ANOVA, F values and $p$ values determined for variables show alkaline dosage $\left(x_{1}\right)$ and irradiated energy $\left(x_{2}\right)$ has near the same strong effect on dielectric constant (Table 3).

Quadratic terms for irradiated energy and interaction effect of variables was not significant; therefore, 


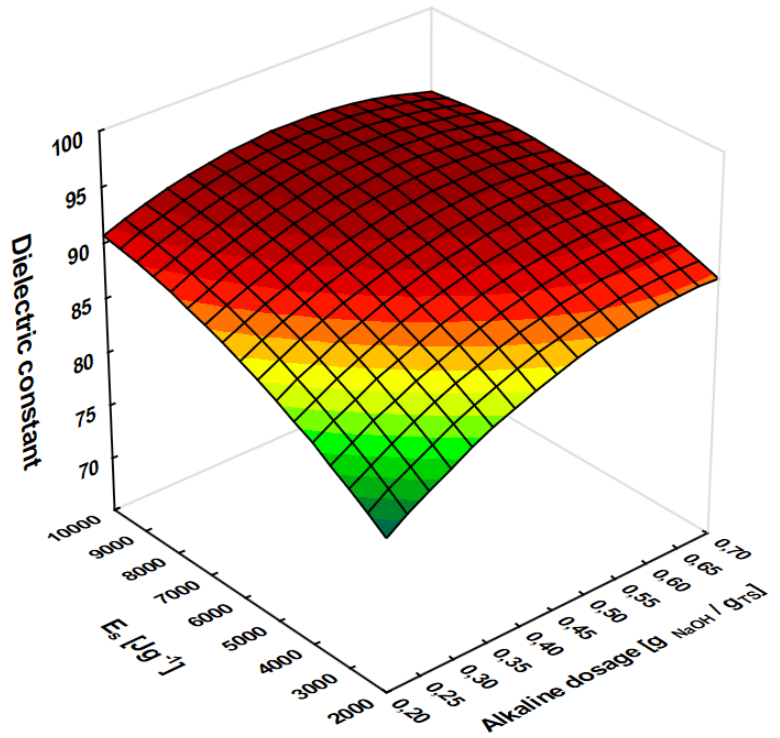

Fig. 3. Response surface for dielectric constant measured at a temperature of $20^{\circ} \mathrm{C}$.

Table 3

ANOVA for dielectric constant

\begin{tabular}{cccccc}
\hline Source & SS & Df & MS & F-value & p-value \\
\hline$x_{1}$ & 98.42 & 1 & 98.42 & 30.94 & 0.0014 \\
$x_{1}{ }^{2}$ & 13.32 & 1 & 13.32 & 6.19 & 0.0027 \\
$x_{2}$ & 101.48 & 1 & 101.48 & 31.90 & 0.0013 \\
$x_{2}{ }^{2}$ & 7.48 & 1 & 7.48 & 2.35 & 0.1760 \\
$x_{1} x_{2}$ & 11.88 & 1 & 11.88 & 3.73 & 0.1015 \\
Error & 19.09 & 6 & 3.18 & & \\
$\mathrm{R}^{2}$ & 0.7513 & & & & \\
\hline
\end{tabular}

the empirical mathematical model for the estimation of dielectric constant $\left(Y_{3}\right)$ contains the linear terms of $E_{s}$ and alkaline dosage [Eq. (11)]. The coefficient of determination was satisfactory $\left(R^{2}=0.7513\right)$, and the predicted value of constructed model agreed with $75 \%$ of experimental data.

$Y_{3}=62.84+63.35 x_{1}-44.17 x_{2}^{2}+0.0033 x_{2}$

\section{Conclusion}

Our research work aimed to examine the effect of combined microwave-alkaline treatment on the disintegration degree (DD) and aerobic biodegradability (BDI) of sludge that originated from meat processing. Considering technical purposes, our research was also extended to the measurement of the change of dielectric constant.

Results verified that in continuous-flow microwave treatment process, disintegration degree of sludge can be enhanced to above $45 \%$, and the irradiated energy and alkaline dosage significantly influenced the efficiency of the process. Microwave-alkaline treatments improved the aerobic biodegradability, but contrary to the observed tendency for change of DD, the higher irradiated MW energy and alkaline dosage over a certain value manifested in worsened BDI. It has been established that investigation of DD alone is not suitable to estimate the change of aerobic biodegradability. Detection of a dielectric constant during combined microwave-alkaline sludge treatments led to valuable results because the change of dielectric constant has a tendency similar to that obtained for disintegration degree. This finding could help develop a dielectric method for real-time estimation of disintegration efficiency during pre-treatment processes.

\section{Acknowledgements}

The authors are grateful for the financial support provided by the NRDI under project number K115691. This project was supported by the János Bolyai Research Scholarship of the Hungarian Academy of Sciences and the UNKP-17-4-I-SZTE-5New National Excellence Program of the Ministry of Human Capacities.

\section{References}

[1] L. Appels, J. Baeyens, J. Degreve, R. Dewil, Principles and potential of the anaerobic digestion of waste-activated sludge, Prog. Energy Combust. Sci., 34 (2008) 755-781.

[2] C. Leonelli, T.J. Mason, Microwave and ultrasonic processing Now a realistic option for industry, Chem. Eng. Proc., 49(9) (2010) 885-900.

[3] J-H. Ahn, S.G. Shin, S. Hwang, Effect of microwave irradiation on the disintegration and acidogenesis of municipal secondary sludge, Chem. Eng. J., 153(1-3) (2009) 145-150.

[4] Q. Yu, H. Lei, Z. Li, H. Li, K. Chen, X. Zhang, R. Liang, Physical and chemical properties of waste-activated sludge after microwave treatment, Wat. Res., 44(9) (2010) 2841-2849.

[5] S. Kavitha, J.R. Banu, J.V. Kumar, M. Rajkumar, Improving the biogas production performance of municipal waste activated sludge via dispenser induced microwave investigation, Biores. Techn., 217 (2016) 21-27.

[6] M. Carlsson, A. Lagerkvist, F. Morgan-Sagastume, The effects of substrate pre-treatment on anaerobic digestion systems: A review, Waste Manage., 32(9) (2012) 1634-1650.

[7] C. Holtze, R. Sivaramakrishnan, M. Antonietti, J. Tsuwi, F. Kremer, K.D. Kramer, The microwave absorption of emulsions containing aqueous micro and nanodroplets: A means to optimise microwave heating, J. Coll. Interface Sci., 302(2) (2006) 651-657.

[8] G. Brodie, R. Destefani, P.A. Schneider, L. Airey, M.V. Jacob, Dielectric properties of sewage biosolids: Measurement and modeling, J. Microw. Power Electromagn. Energy, 48(3) (2014) 147-157.

[9] A.A. Barba, M. d'Amore, Relevance of dielectric properties in microwave-assisted processes. In. Microwave Materials Characterization, Ed. S. Costanzo., 2012, InTech.

[10] I. Dogan, F.D. Sanin, Alkaline solubilisation and microwave irradiation as a combined sludge disintegration and minimisation method, Water Res., 43(8) (2009) 2139-2148.

[11] A. Serrano, J.A. Siles, M.A. Martin, A.F. Chica, F.S. Estevez-Pastor, E. Toro-Baptista, Improvement of anaerobic digestion of sewage sludge through microwave pre-treatment, J. Environ. Manag., 177 (2016) 231-239.

[12] G. Cuccurullo, L. Giordano, G. Viccione, An analytical approximation for continuous flow microwave heating of liquids, Adv. Mech. Eng., 2013, Article ID 929236.

[13] C.O. Kappe, Controlled microwave heating in modern organic synthesis, AngewandteChemie, 43 (2004) 6250-6284. 
[14] M. Damm, C. Nusshold, D. Cantillo, G.N. Rechberger, K. Grubel, W. Sattler, C.O. Kappe, Can electromagnetic fields influence the structure and enzymatic digest of proteins? A critical evaluation of microwave-assisted proteomics protocols, J. Proteom., 75(18) (2012) 5533-5543.

[15] Q. Yang, J. Yi, K. Luo, X. Jing, X. Li, Y. Liu, G. Zeng, Improving disintegration and acidification of waste activated sludge by combined alkaline and microwave pretreatment, Proc. Safety Environ. Protect., 91(6) (2013) 521-526.

[16] P. Zhang, G. Zhang, W. Wang, Ultrasonic treatment of biological sludge: Floc disintegration,cell lysis and inactivation, Bioresour. Technol., 98(1) (2007) 207-210.

[17] S. Beszédes, L. Ludányi, G. Szabó, C. Hodúr, Microwave enhanced biodegradability of meat processing wastewater sludge, Environ. Eng. Manag. J., 16(1) (2017) 149-155.

[18] A.V. Ebenezer, P. Arulazhagan, S.A. Kumar, I.-T. Yeom, J.R. Banu, Effect of deflocculation on the efficiency of low-energy microwave pretreatment and anaerobic biodegradation of waste activated sludge, Appl. Energy, 145 (2015) 104-110.

[19] J.H. Jang, J.H. Ahn, Effect of microwave pretreatment in presence of $\mathrm{NaOH}$ on mesophilic anaerobic digestion of thickened waste activated sludge, Biores. Technol., 131 (2013) 437-442.

[20] R.U. Rani, S.A. Kumar, S. Kalippan, I. Yeaom, J.R. Banu, Impacts of microwave pretreatments on the semi-continuous anaerobic digestion of dairy waste activated sludge, Waste Manag., 33 (2013) 1119-1127.

[21] S. Kavitha, J.R. Banu, J.V Kumar, M. Rajkumar, Improving the biogas production performance of municipal waste activated sludge via dispenser induced microwave investigation, Biores. Techn., 217 (2016) 21-27.

[22] A.V. Ebenezer, S. Kaliappan, S.A. Kumar, I.-T. Yeom, J.R. Banu, Influence of deflocculation on microwave disintegration and anaerobic biodegradability of waste activated sludge, Biores. Techn., 185 (2015) 194-201.
[23] A.M. Yeneneh, A. Kayaalp, T.K. Sen, H.M. Ang, Effect of microwave and combined microwave-ultrasonic pretreatment on anaerobic digestion of mixed real sludge, J. Environ. Chem. Eng., 3(4) (2015) 2514-2521.

[24] C. Eskicioglu, N. Terzian, K.J. Kennedy, R.L. Droste, M. Hamoda, Athermal microwave effects for enhancing digestibility of waste activated sludge, Wat. Res., 41(11) (2007) 2457-2466.

[25] Y. Chi, Y. Li, X. Fei, S. Wang, H. Yuan, Enhancement of thermophilic anaerobic digestion of thickened waste activated sludge by combined microwave and alkaline pretreatment, J. Environ. Sci., 23(8) (2011) 1257-1265.

[26] B.A. Alagöz, O. Yenigün, A. Erdicler, Enhancement of anaerobic digestion efficiency of wastewater sludge and olive waste: Synergistic effect of co-digestion and ultrasonic/microwave sludge pre-treatment, Waste Manag., 46 (2015) 182-188.

[27] J. Dwyer, D. Starrenburg, S. Tait, K. Barr, D.J. Batstone, P. Lant, Decreasing activated sludge thermal hydrolysis temperature reduces product colour, without decreasing degradability, Wat. Res., 42(18) (2008) 4699-4709.

[28] M. Takashima, Y. Tanaka, Acidic thermal post-treatment for enhancing anaerobic digestion of sewage sludge, J. Environ. Chem. Eng., 2(2) (2014) 773-779.

[29] D.A. Mendis, M. Rosenberg, F. Azam, A note on the possible electrostatic disruption of bacteria, IEE Trans. Plasma Sci., 28(4) (2000) 1304-1306.

[30] R. Wang, P. Zheng, A. Ding, M. Zhang, A. Ghulam, C. Yang, H-P. Zhao, Effects of inorganic salts on denitrifying granular sludge: The acute toxicity and working mechanisms, Biores. Techn., 204 (2016) 65-70.

[31] R. Fuentes-Azcatl, N. Mendoza, J. Alejandre, Improved SPC force field of water based on dielectric constant: SPC/e. Physica A: Stat. Mech Applic., 420 (2015) 116-123. 